\title{
Severe inflammatory reaction induced by peritoneal trauma is the key driving mechanism of postoperative adhesion formation
}

\author{
Sergei V Pismensky ${ }^{1,2+}$, Zhomart R Kalzhanov ${ }^{5 \dagger}$, Marina Yu Eliseeva ${ }^{3,4}$, loannis P Kosmas ${ }^{6}$ and Ospan A Mynbaev ${ }^{2,3^{*}}$
}

\begin{abstract}
Background: Many factors have been put forward as a driving mechanism of surgery-triggered adhesion formation (AF). In this study, we underline the key role of specific surgical trauma related with open surgery (OS) and laparoscopic (LS) conditions in postoperative AF and we aimed to study peritoneal tissue inflammatory reaction (TIR), remodelling specific complications of open surgery (OS) versus LS and subsequently evaluating AF induced by these conditions.
\end{abstract}

Methods: A prospective randomized study was done in 80 anaesthetised female Wistar rats divided equally into 2 groups. Specific traumatic OS conditions were induced by midline incision line (MIL) extension and tissue drying and specific LS conditions were remodelled by intraperitoneal $\mathrm{CO}_{2}$ insufflation at the $10 \mathrm{~cm}$ of water. TIR was evaluated at the $24^{\text {th }}, 72^{\text {nd }}, 120^{\text {th }}$ and $168^{\text {th }}$ hour by scoring scale. Statistical analysis was performed by the nonparametric $t$ test and two-way ANOVA using Bonferroni post-tests.

Results: More pronounced residual TIR was registered after OS than after LS. There were no significant TIR interactions though highly significant differences were observed between the OS and LS groups $(p<0.0001)$ with regard to surgical and time factors. The TIR change differences between the OS and LS groups were pronounced with postoperative time $p<0.05$ at the $24^{\text {th }}$ and $72^{\text {nd }} ; p<0.01-120^{\text {th }}$ and $p<0.001-168^{\text {th }}$ hrs. Adhesion free wounds were observed in 20.0 and $31.0 \%$ of cases after creation of OS and LS conditions respectively; with no significant differences between these values ( $p>0.05)$. However larger adhesion size $(41.67 \pm 33.63)$ was observed after OS in comparison with LS (20.31 \pm 16.38). The upper-lower 95\% confidential limits ranged from 60.29 to 23.04 and from 29.04 to 11.59 respectively after OS and LS groups with significant differences $(p=0.03)$. Analogous changes were observed in adhesion severity values. Subsequently, severe TIR parameters were followed by larger sizes of severe postoperative adhesions in the OS group than those observed in the LS group.

Conclusions: MIL extension and tissue drying seem to be the key factors in the pathogenesis of adhesion formation, triggering severe inflammatory reactions of the peritoneal tissue surrounding the MIL resulting in local and systemic consequences. $\mathrm{CO}_{2}$ insufflation however, led to moderate inflammation and less adhesion formation.

\section{Background}

Adhesions are an important health care problem [1-5], causing long term postsurgical complications such as infertility, pelvic pain and bowel obstructions, Therefore, a broad spectrum of approaches has been tested to prevent postsurgical adhesion formation albeit with unequivocal results $[6,7]$.

\footnotetext{
* Correspondence: ospanmynbaev@hotmail.com

+ Contributed equally

${ }^{2}$ The Experimental Research \& Modeling Division, Moscow State University of Medicine \& Dentistry, Delegatskaya str 20/1, Moscow, 127473, Russia Full list of author information is available at the end of the article
}

Laparoscopy (LS) has been established as the golden standard for the surgical treatment of a variety of benign tumors and other pathologic conditions. Laparotomy or open surgery (OS) is increasingly being regarded as outdated and thus may not be the treatment of choice of many pathologic conditions in the abdominal and pelvic cavities for much longer. Many studies have been comparatively evaluating perioperative changes, as well as short and long term outcomes of OS versus LS [8-10]. In order to describe and calculate the mobility of the abdominal wall and the nature of the underlying disturbances, Stumpf et al [11] used three-dimensional

\section{Biomed Central}


stereography, which is a noninvasive optical method of measuring surface areas. They measured pre- and postsurgery abdominal wall mobility in patients undergoing LS and OS surgery and found a significant difference in abdominal wall mobility between patients treated by LS in comparison with those treated by OS. Abdominal movement was completely recovered the $7^{\text {th }}$ day after LS, whereas a significant lack of mobility was still observed the $12^{\text {th }}$ day after OS. Consequently, the minimal invasive approach presented a positive effect on abdominal wall integrity.

It is well known that LS, compared with OS, reduces adhesion formation. Therefore, many contradicting findings have been presented and discussed concerning LSrelated postoperative adhesion formation mechanisms [12]. Generally accepted mechanisms of adhesion formation after OS, including tissue ischemia and decreased tissue plasminogen activator (tPA activity) with subsequent transition of persistent fibrinoid adhesions (deposits) to permanent fibrous adhesions were automatically copied to LS [13-16]. $\mathrm{CO}_{2}$ insufflation was presumed a co factor of adhesion formation since during laparoscopic procedures surgeons can perform manipulations due to the creation of $\mathrm{CO}_{2}$-pneumoperitoneum $[17,18]$.

However, both OS and LS have their specific traumatic effects on the abdominal wall and peritoneum tissue. OS has more additional traumatic effects related with the midline incision line (MIL) giving access to the operated organs, tissue drying, direct hand-manipulations, accumulation of foreign bodies and severe tissue ischemia by MIL extension, ligations and suturing of the abdominal wound. Most of these tissue traumatic factors are reduced or excluded during LS with subsequent beneficial outcome such as fast postsurgical recovery, less morbidity, pain decrease etc. $[9,10,19]$. Therefore, the starting point of our study was that we should inflict the same initial abdominal wall trauma to two groups of rats. Then we would perform OS in one group and LS in another. We presumed that the more pronounced impact of OS on postoperative complications, such as adhesion formation, would be clearly defined in the models of the OS with MIL extension and tissue drying and aimed to study peritoneal tissue inflammatory reaction (TIR), remodelling specific complications of OS versus LS and subsequently evaluating of adhesions induced by these conditions.

\section{Methods \\ Animals}

The experimental protocol was approved by the M.V. Lomonosov Moscow State University Review Board and Animal Care Committee as a part of the research project of MD thesis by SVP.

The animals were kept under standard laboratory conditions at a temperature between 20 and $25^{\circ} \mathrm{C}$, and a relative humidity of 40 to $70 \%$. They had a day cycle of $14 \mathrm{~h}$ light and $10 \mathrm{~h}$ dark, a standard laboratory diet and free access to food and water. The animals were housed at the Laboratory for Animal Care, Faculty of Basic Medicine, M. V. Lomonosov Moscow State University, Moscow, Russia).

\section{Experimental design}

The experiment was done by a blind randomization in anaesthetised spontaneously breathing 80 adult female 6 month old Wistar rats weighing between 210-230 g divided equally into 2 groups (Table 1): laparotomy or OS group and LS group. 19 rats were excluded from final analysis since they died before the first evaluation (10 from OS and 9 - LS). Animals were euthanized at the $24^{\text {th }}, 72^{\text {nd }}$, $120^{\text {th }}$ and $168^{\text {th }}$ hours after surgery with intramuscular injection of toxic doses $(100 \mathrm{mg} / \mathrm{kg})$ of Thiopental Sodium and the severity of the peritoneal inflammatory reactions was studied by a scoring system. Postsurgical adhesions were evaluated in all animals examined after 168 hours of surgery.

\section{Anaesthesia and surgical procedures}

Anaesthesia was achieved and maintained by intramuscular fractional injection of thiopental sodium in the musculus femoralis $(50 \mathrm{mg} / \mathrm{kg})$ and inhalation of air.

According to our study design, surgical procedures included similar adhesion inducing trauma i.e. MIL, in the first step in both groups. Then MIL extension was performed in the OS group as a simulation of basic specific traumatic conditions related with laparotomy. $\mathrm{CO}_{2}$ was insufflated in the LS group as a main specific condition is related with laparoscopy.

Table 1 Design of surgical procedures and evaluation methods in both OS and LS groups

\begin{tabular}{lll}
\hline $\begin{array}{l}\text { Adhesion inducing } \\
\text { trauma }\end{array}$ & $\begin{array}{l}\text { Simulation of basic specific surgical } \\
\text { conditions } \\
\text { during } 1 \mathrm{hr}\end{array}$ & \multicolumn{1}{c}{ Time of evaluation and type of results } \\
\cline { 2 - 3 } MIL & MIL extension & $\begin{array}{l}\text { Postsurgical follow up of inflammation } \\
\text { severity }\end{array}$ \\
\cline { 2 - 3 } & $\mathrm{CO}_{2}$ insufflation at $10 \mathrm{~cm}$ of water & \\
and size
\end{tabular}


In the OS group a $2 \mathrm{~cm}$ MIL was performed by scalpel and the abdominal cavity was kept open for 1 hour with extension of the MIL by eye retractor. The same MIL was performed in the LS group to induce adhesion formation in the trocar sites and $18 \mathrm{~g}$ catheter "HELMFLON ${ }^{\circledR} /$ HELMSYTE $^{\circledR}$ " of the company HELM India PVT Ltd was fixed in the middle of the MIL. Consequently, this MIL was closed without extension. $\mathrm{CO}_{2}$ was insufflated during 1 hour through this catheter to simulate laparoscopic conditions during $\mathrm{CO}_{2}$ pneumoperitoneum and the wound around this catheter was considered as a port-site wound. The MIL was closed by two layers of continuous sutures of vicril 5/0 (Ethicon, Johnson \& Johnson) in both groups. The first suture layer included peritoneum, musculus and fascia; the second layer - only the skin.

\section{$\mathrm{CO}_{2}$-pneumoperitoneum setup}

To insufflate $\mathrm{CO}_{2}$ a special setup (Figure 1) was designed, consisting of the $\mathrm{CO}_{2}$ balloon (1), a T-figurative metal tube with different tubes connected to different devices including, connection tubes $(2,3)$ a water valve (4). This setup also includes the humidifier (5) and heating device (6) with thermometer (7) and the excess water reservoir (8).

The heating device, the thermometer and the excess water reservoir controlled the temperature and humidity of the $\mathrm{CO}_{2}$ gas. The temperature in this system was kept at $37^{\circ} \mathrm{C}$. The temperature in animals' body was kept by the permanent flow of warmed and humidified
$\mathrm{CO}_{2}$ to keep intraperitoneal pressure level at the $10 \mathrm{~cm}$ of water. Animals' body temperature was above $35^{\circ} \mathrm{C}$ outside of their skin. Excess water after condensation accumulated in the special reservoir, and warm and humidified $\mathrm{CO}_{2}$ gas was administered through a distributor (9) with 5 small tubes connected with the let in $18 \mathrm{G}$ catheter (10) which was inserted into the rats' abdomen (11).

Insufflation pressure was controlled and monitored with two water valves. The first water valve (4), which was situated next to the $\mathrm{CO}_{2}$ balloon and controlled the pressure in the insufflation system. The abdominal cavity of the animals was connected through the outlet 20 G catheter (12) with a second water valve (13) to monitor the intra-abdominal pressure. When the intraperitoneal pressure was achieved $10 \mathrm{~cm}$ of water excess of $\mathrm{CO}_{2}$ was deflated by means of the second water valve (13). The $\mathrm{CO}_{2}$-pneumoperitoneum was simultaneously created simultaneously in 5 animals.

\section{Evaluation of macroscopic changes and adhesion formation}

The severity of the peritoneal inflammatory reactions was studied by a scoring system (Table 2) in 5 rats in each group at the first three time points 24,72 and 120 hr and in 16 and 15 animals in OS and LS groups respectively at the $168^{\text {th }} \mathrm{hr}$ after surgery. A sum of individual inflammation parameter scores was calculated as the total inflammation score for each animal and its

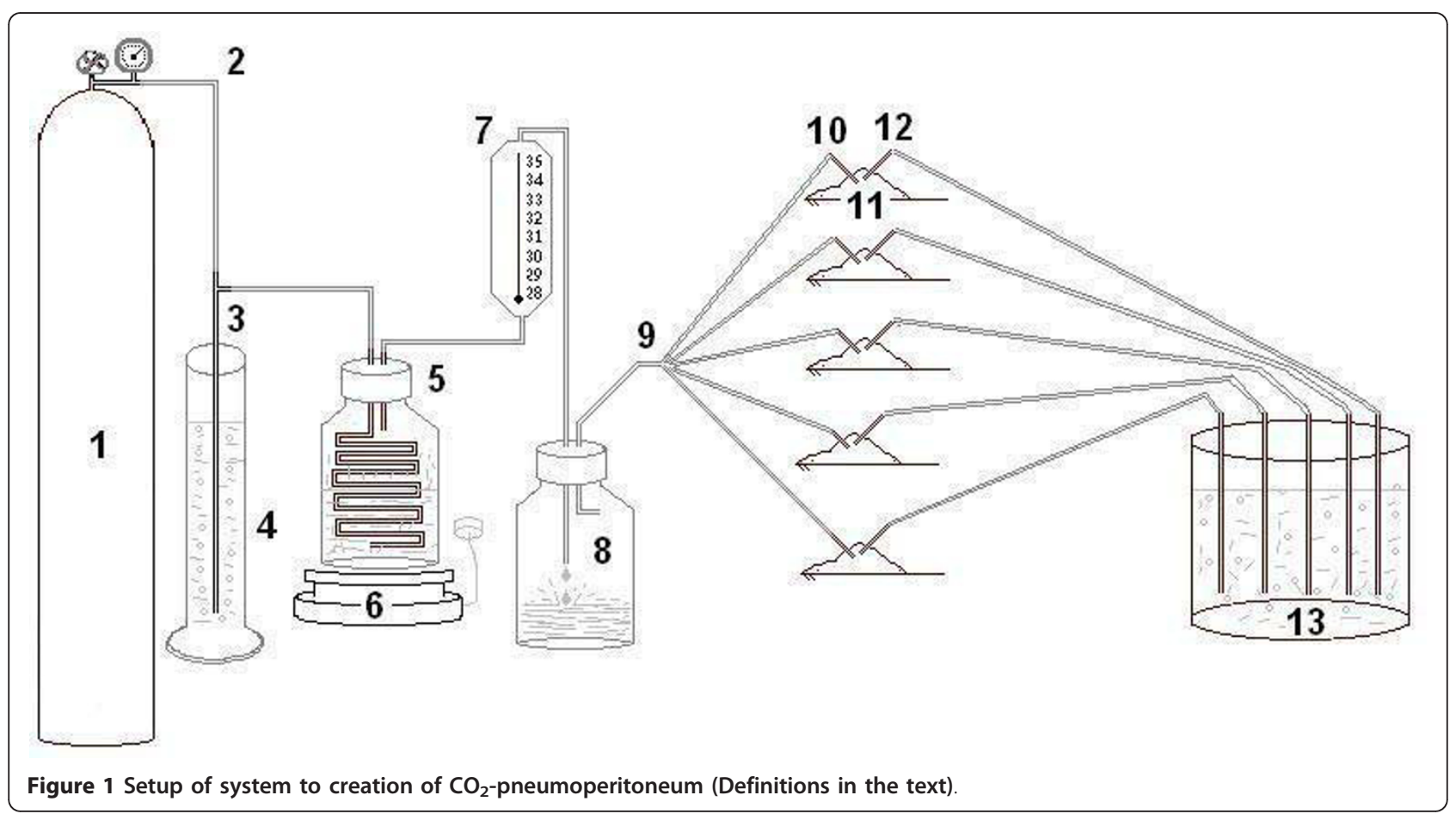


Table 2 Macroscopic residual inflammatory reaction scoring system

\begin{tabular}{llc}
\hline & \multicolumn{1}{c}{ Parameters } & Scores \\
\hline $\begin{array}{ll}\text { Smooth wound surface with palish or palish-pink color of } \\
\text { serosa }\end{array}$ & 0.5 \\
\cline { 2 - 3 } Hyperemia & Dilated vessels & 0.5 \\
\cline { 2 - 3 } & Petechial extravasation/hemorrhage & 0.5 \\
\cline { 2 - 3 } & Hematoma & 0.5 \\
\cline { 2 - 3 } & Hemorrhagic imbibition & 0.5 \\
\hline Black blue color of wound & 0.5 \\
\hline Edema & 0.5 \\
\hline Fibrinoid deposits on the wound surfaces & 0.5 \\
\hline Necrotic tissue and detritus & 0.5 \\
\hline Fester and other changes & \\
\hline Total score
\end{tabular}

mean and standard deviation (SD) values in OS and LS groups were analyzed in different postsurgical time points.

To objectively present the relief of adhesions in the abdominal and pelvic cavity we carefully evaluated the frequency and character of adhesions on the laparotomy line, on the uterine horns, on the area of the peritoneal adhesion formation model and on the other abdominal and pelvic structures/organs. These data were recorded by a researcher blinded to the treatment groups. The adhesion size was observed as follows: 0 - no adhesions; $1-25 \%$; $26-$ $50 \%$; $51-75 \%$ of traumatized area or total $(76-100 \%)$ involvement. Adhesion severity was recorded as follows: 0 - no adhesions; 1 - no resistance to separation; 2 - little resistance to separation; 3 - moderate resistance (force required) to separation; 4 - sharp dissection needed to separation.

\section{Randomization}

Groups were formed randomly and after the creation of a model, the assistants marked the animals. After filling in the individual protocol of surgical procedures for each animal, these protocols were each put in a separate envelope, which was sealed immediately. After $168 \mathrm{hr}$, the animals were randomly picked for the evaluation. One outsider surgeon (MYuE) and OAM managed this procedure. Each animal was separately evaluated simultaneously by two researchers. There were only 5 cases of disarrangements and those cases were repetitively evaluated to find consensus. Then, a new protocol of adhesion formation for each animal was filled in and, finally, after the experiment had ended, it was matched with the first protocol which was filled after the previous surgery.

\section{Statistics}

Statistical analysis was performed by Graph Pad Prism. Mean \pm SD is indicated unless stated otherwise. P values were obtained by two-way ANOVA using Bonferroni post-tests for repeated inflammation values and the unpaired $t$ test for adhesion frequency, size and severity. We performed the Kolmogorov \& Smirnov normality test to find out data sampled from populations that follow Gaussian distribution. Data concerning adhesion size as well as adhesion severity passed this test, but data concerning adhesion frequency did not. Using twoway ANOVA with Bonferroni post-tests we tried to answer the following questions:

$1)$. Does the surgery have the same effect at all values of time (24, 72, 120 and $168 \mathrm{hr})$ ?

2 ). Does the surgery affect the result or are the curves different?

3). Does time affect the result or are the curves horizontal?

\section{Results}

More pronounced residual peritoneal tissue inflammatory reaction parameters were registered after OS in comparison with those after LS (Figure 2).

1) Interaction accounts for approximately $1.61 \%$ of the total variance $(\mathrm{F}=1.19, \mathrm{DFn}=3, \mathrm{DFd}=53$ and $\mathrm{p}=$ 0.32 ). If there is no interaction overall, there is a $32 \%$ chance of randomly observing effect. Subsequently the interaction is considered not significant.

2) Surgery accounts for approximately $26.53 \%$ of the total variance $(\mathrm{F}=58.53, \mathrm{DFn}=1, \mathrm{DFd}=53$ and $\mathrm{p}=$ 0.0001 ). If the surgery has no effect overall, there is a less than $0.01 \%$ chance of randomly observing effect. Subsequently, the surgical impact is considered extremely significant.

3) Time accounts for approximately $32.33 \%$ of the total variance $(\mathrm{F}=23.77, \mathrm{DFn}=3, \mathrm{DFd}=53$ and $\mathrm{p}=$ 0.0001). If time has no effect overall, there is a less than $0.01 \%$ chance of randomly observing effect. The effect of time is also considered to be extremely significant.

There were no significant interactions in peritoneal tissue inflammatory reaction parameters, but highly significant differences were observed between the OS and LS groups $(\mathrm{p}<0.0001)$ with regard to both surgical and time factors. The differences of changes in peritoneal tissue inflammatory reaction parameters between OS and LS groups were pronounced with postoperative time $\mathrm{p}<0.05$ at the $24^{\text {th }}$ and $72^{\text {nd }} ; \mathrm{p}<0.01-120^{\text {th }}$ and $\mathrm{p}<0.001-168^{\text {th }}$ hrs.

The adhesion frequency was studied as follows, the presence of adhesions was considered as 1 , absence - as 0 (Figure 3A). Subsequently, we found an average value of wounds covered by adhesions in $0.80 \pm 0.41$ and 0.69 \pm 0.48 of cases after the creation of OS and LS conditions respectively. There were no significant differences between these values by unpaired $t$ test (the two-tailed $p$ 


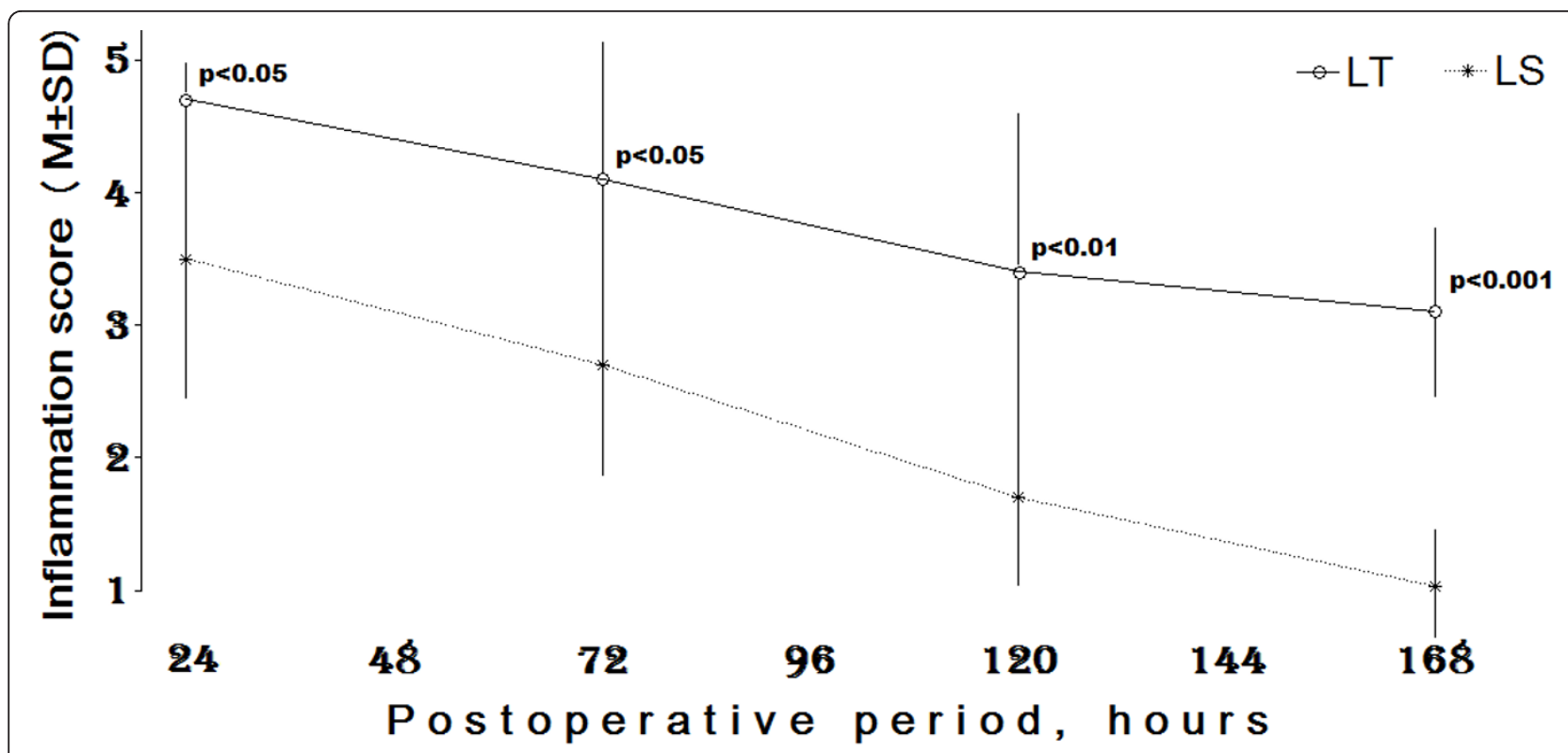

Figure 2 Dynamics of postoperative inflammation score changes after induction conditions of open and laparoscopic surgery. $P$ value (LT vs LS) was obtained by two-way ANOVA with Bonferroni post-tests.

$=0.49)$. However, larger adhesion size $(41.67 \pm 33.63 \%)$ was observed after OS (Figure 3B) in comparison with LS $(20.31 \pm 16.38 \%)$. The upper-lower $95 \%$ confidential limits ranged from 60.29 to 23.04 and from 29.04 to 11.59 respectively after OS and LS groups, with significant differences by unpaired $t$ test (the two-tailed $\mathrm{p}=$ 0.03).

The mean value of adhesion severity (Figure 3C) was significantly higher in the OS group in comparison with the analogous parameter of the LS group: respectively $2.4 \pm 1.55$ and $1.31 \pm 1.35$ scores, with the upper-lower $95 \%$ confidential limits ranging from 3.26 to 1.54 and from 2.03 to 0.59 (the two-tailed $p=0.03$ ). Subsequently, results for the TIR parameters ran parallel with this finding showing larger size and severe postoperative adhesions in the OS group compared with those observed in the LS group.

\section{Discussion}

Both open and laparoscopy surgery trigger specific traumatic effects related with removing tumors or with surgical treatment of other diseases of the abdominal cavity (Table 3). On the basis of literature it is suggested that open surgery results in more additional traumatic effects due to the following conditions and complications [16,20-23]:

$\checkmark$ extension of the laparotomy incision of the abdominal wall to get access to the operated organ;

$\checkmark$ tissue drying due to open abdomen and prolonged surgery; $\checkmark$ direct hand-manipulations, handling of the abdominal organs and tissue;

$\checkmark$ accumulation of foreign bodies - small pieces of surgical materials, tampons, plugs, napkins, suture materials

$\checkmark$ severe tissue ischemia related with ligation and suturing as well as extension of the laparotomy incision of the abdominal wall;

$\checkmark$ the possibility of bacterial contamination, which cannot be excluded.

However, laparoscopic surgery entails other, specific effects due to the use of gas media to extend the abdomen. From this, a large body of literature has sprung studying the pathophysiologic mechanisms of $\mathrm{CO}_{2}-$ pneumoperitoneum induced systemic alterations such as respiratory, cardiovascular and blood gas, acid base parameters changes, as well as local disturbances in the peritoneal cavity such as decreased peritoneal $\mathrm{pH}$ and blood circulatory deteriorations with mesothelial hypoxemia during laparoscopic surgery [24-29]. The discussion has polarised: some claim these changes have a crucial impact on postsurgical complications such as adhesion formation and port-site cancer metastasis [30-34] others say these changes have no or little impact on postsurgical complications [16,17,28,29].

Recently, these two approaches have been systematically compared in malignant conditions in several metaanalyses. The mean operative time for LS was significantly longer but the postoperative hospital stay was shorter in comparison with those undergoing 


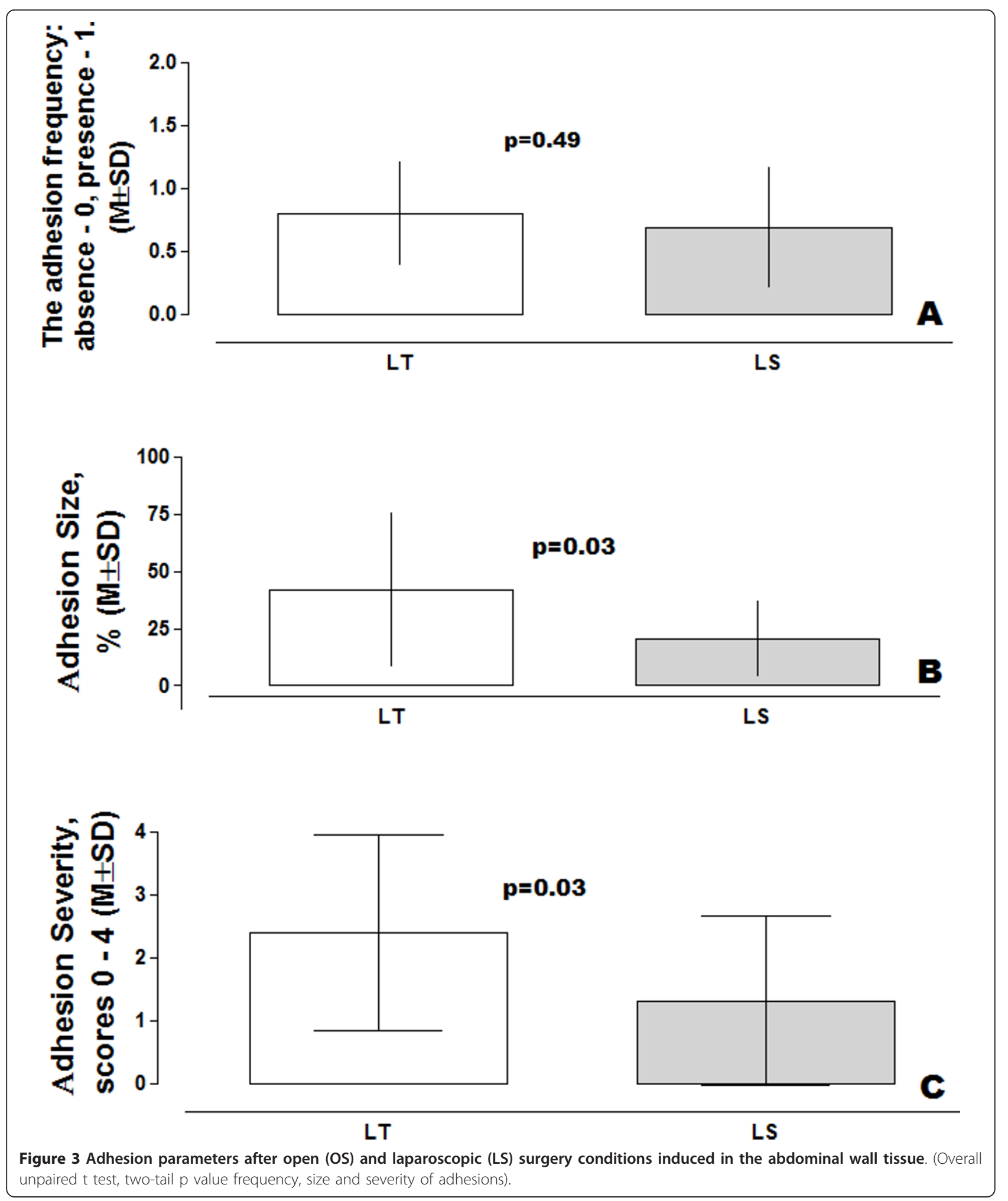

laparotomy in a meta-analysis of 2940 patients with splenectomy drawn from a large amount of publications [19]. Subsequently, it was concluded that laparoscopy is associated with a significant reduction in splenectomy- related morbidity, primarily as a function of fewer complications (pulmonary, wound, and infectious). In another meta-analysis of randomized controlled trials of LS versus laparotomy in patients with endometrial 
Table 3 Open and laparoscopy surgery-related factors and consequences of the surgical treatment of diseases in the abdominal and pelvic cavities

\begin{tabular}{lll}
\hline Factors & Laparotomy & Laparoscopy \\
\hline Procedures & $\begin{array}{l}\text { Midline incision } \\
\text { Extension of the midline } \\
\text { incision }\end{array}$ & $\begin{array}{l}\text { Trocar or port sites } \\
\mathrm{CO}_{2} \text { pneumoperitoneum } \\
\text { Indirect hand-manipulations }\end{array}$ \\
& Direct hand-manipulations & \\
\hline $\begin{array}{l}\text { Intrasurgical } \\
\text { damaging }\end{array}$ & Tissue drying & $\mathrm{CO}_{2}$ pneumoperitoneum-related local and systemic effects: blood gas, acid base balance parameters \\
factors & Severe trauma & changes, blood circulatory in large vessels and parenchymatous organs in the abdominal and pelvic \\
& Severe ischemia & cavities \\
& Accumulation of foreign & \\
& bodies & \\
& The possibility of bacterial & \\
\hline Consequences & Painful slow recovery & Less painful fast recovery \\
& High morbidity & Low morbidity \\
& Long hospitalization & Short hospitalization \\
& A big scar & Small scars \\
\hline
\end{tabular}

cancer, LS was associated with fewer postoperative complications, lower transfusion incidence, less blood loss, longer operation time, and shorter hospital stay [9]. Moreover, no significant differences in terms of recurrence and survival were found. Subsequently, LS was thought to be a better choice than OS if it is performed by suitably specialized surgeons in selected patients. Recently, quite striking contrasting findings were presented by Leroy et al [8] with reports of increased conversion rates and a laparoscopic colectomy risk in obese patients $\left(\mathrm{BMI}>30 \mathrm{~kg} / \mathrm{m}^{2}\right)$. It was concluded that LS for left colon resections is as feasible and at least as safe in non-obese patients and the benefits of the laparoscopic approach depending on the implementation of a highly standardized surgical technique.

Most of these tissue traumatic factors are reduced or excluded during laparoscopy with the subsequent beneficial outcome. Due to the fast recovery after surgery, less morbidity, decreased pain etc, laparoscopy is now also being applied in the treatment of malignant but curable conditions resulting in equally beneficial results in the short-time follow-up for patients with malignant cancers.

More pronounced residual peritoneal tissue inflammatory reaction parameters were registered after open surgery, as compared with LS. There were no significant interactions in peritoneal tissue inflammatory reaction parameters, but highly significant differences were observed between the open surgery and LS groups ( $\mathrm{p}<$ 0.0001 ) with regard to both treatment and time factors by two-way ANOVA with source of variation and Bonferroni post-tests. The differences in peritoneal tissue inflammatory reaction changes between the open surgery and LS groups were pronounced with postoperative time $\mathrm{p}<0.05$ at the $24^{\text {th }}$ and $72^{\text {nd }} ; \mathrm{p}<0.01-120^{\text {th }}$ and $\mathrm{p}<$ $0.001-168^{\text {th }}$ hrs.
We found adhesion free wounds in approximately 20.0 and $31.0 \%$ cases after creation of open surgery and LS conditions respectively. There were no significant differences between these values by unpaired t test $(p>0.05)$. However, larger adhesion size $(41.67 \pm 33.63)$ was observed after open surgery in comparison with LS (20.31 \pm 16.38$)$. The upper-lower 95\% confidential limits ranged from 60.29 to 23.04 and from 29.04 to 11.59 respectively after open surgery and LS with significant differences by unpaired two-tail t test $(\mathrm{p}=0.03)$. Subsequently, a severe peritoneal tissue inflammatory reaction arose, due to the larger size of the postoperative adhesions in the open surgery group than those observed in the LS group respectively: $2.4 \pm 1.55$ and $1.31 \pm 1.35$ scores with the upperlower $95 \%$ confidential limits from 3.26 to 1.54 and from 2.03 to 0.59 (the two-tailed $\mathrm{p}=0.03$ ).

Since excess $\mathrm{CO}_{2}$ is immediately eliminated through the lungs (Figure 4) by increased breathing, in our opinion $\mathrm{CO}_{2}$ is the most convenient physiological gas. Our results did not support the impact of $\mathrm{CO}_{2}$-pneumoperitoneum as a co-factor in postsurgical adhesion formation. We found severe peritoneal tissue inflammatory reaction due to surgical trauma resulting from the significantly larger size of postoperative adhesions in the open surgery group. Surprisingly, these observations are in accordance with results published by our colleagues from KULeuven [35].

\section{Conclusion}

Midline laparotomy extension and tissue drying seem to be the key factors in the pathogenesis of postsurgical complications. They trigger severe inflammatory reactions of the peritoneal tissue surrounding the laparotomic incision resulting in local and systemic consequences, whereas $\mathrm{CO}_{2}$ insufflation results in moderate inflammation and less adhesion formation. 


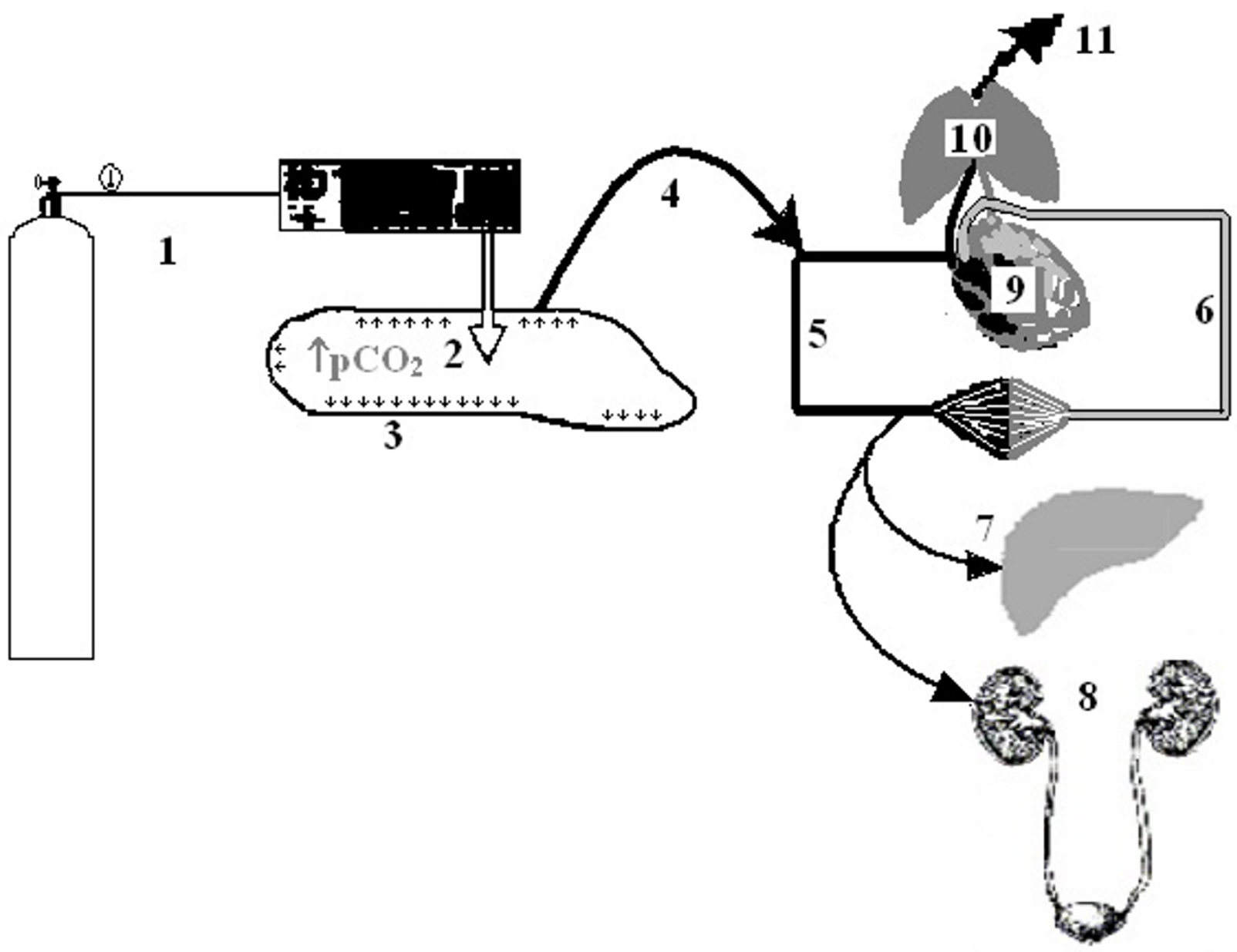

Figure 4 The pathways of $\mathrm{CO}_{2}$ insufflation, diffusion, circulation; and elimination during laparoscopy with $\mathrm{CO}_{2}$ pneumoperitoneum and its pathological effects. $1-\mathrm{CO}_{2}$ insufflation set up (including $\mathrm{CO}_{2}$ balloon and $\mathrm{CO}_{2}$ insufflator); 2 - increased tension of free $\mathrm{CO}_{2}$ gas $\left(\uparrow \mathrm{pCO}_{2}\right)$ in the abdominal cavity; $3-\mathrm{CO}_{2}$ diffusion into parietal peritoneum tissue $\left({ }^{\uparrow \uparrow \uparrow}\right) ; 4$ - passes into capillaries and vessels; $5,6-\mathrm{CO}_{2}$ accumulation and circulation in venous (5) and arterial (6) blood; 7 and 8 - circulatory and functional disturbances in parenchimateous organs (liver and kidney); 9 and 10 - cardiovascular and respiratory changes (heart and lungs); $11-\mathrm{CO}_{2}$ elimination by physiologic way.

\section{List of abbreviations used}

AF: adhesion formation; LS: laparoscopy and laparoscopic conditions; MIL: midline incision line; OS: open surgery; TIR: tissue inflammatory reaction; tPA: tissue plasminogen activator; hr: hour; hrs: hours.

\section{Acknowledgements}

We sincerely thank Veronique Berkein, MA, for her help during the preparation of this manuscript. We are also grateful to Ass. Prof. Lyudmila V. Liutova, BS, PhD, and Prof. Vladimir B. Koshelev BS, PhD, ScD for their help to set up of our experiments in the Laboratory of Fermentative Fibrinolysis, Faculty of Biology and in the Laboratory of Pathophysiology, Faculty of Basic Medicine, Moscow State University.

\section{Author details}

'Laboratory of Pathophysiology, Faculty of Basic Medicine and Laboratory of Fermentative Fibrinolysis, Faculty of Biology, M.V. Lomonosov Moscow State University, Lomonosovsky Prospekt 31-5, Moscow, 117192, Russia. ${ }^{2}$ The Experimental Research \& Modeling Division, Moscow State University of Medicine \& Dentistry, Delegatskaya str 20/1, Moscow, 127473, Russia. ${ }^{3}$ Department of Obstetrics and Gynecology, the Institute of Advanced Training of the Federal Medical-Biological Agency of Russia, Volokalamsky road 30, Moscow, 123182, Russia. ${ }^{4}$ The Institute of Reproductive
Technologies AltraVita, Nagornaya 4A, Moscow, 117186, Russia. ${ }^{5}$ Department of Pediatrics, Faculty of Pediatrics, A.D. Asfendiyarov Kazakh National Medical University, Tole bi street 88, Almaty, 050012, The Republic of Kazakhstan. ${ }^{6}$ Laboratory of Physiology, Faculty of Medicine, University of loannina, loannina, 45110, Greece.

\section{Authors' contributions}

SVP \& ZhRK - equally participated in all steps of surgical procedures, preparation of rats for anaesthesia, surgery and postsurgical animal care, as well as randomization of animals and filling in surgical protocols and interpretation of obtained results. MYuE - was involved in the surgical procedures as an outsider surgeon to blindly evaluate of inflammation and adhesions' parameters by scoring scales, and later she was also participated in the drafting of the manuscript and revising it critically for content. IPK was involved in the design of the study, performed the statistical analysis, interpretation of results. He drafted the manuscript and revised it critically for content. OAM - as a coordinator and a principal researcher has made substantive intellectual contributions to the concept and design of this study, acquisition of data - a creation of surgical models and a blind evaluation of inflammation and adhesions' parameters by scoring scales, statistical analysis and interpretation of this study. All authors read and approved the final manuscript. 


\section{Competing interests}

The authors declare that they have no competing interests.

Received: 6 March 2011 Accepted: 14 November 2011

Published: 14 November 2011

\section{References}

1. Al-Jaroudi $D$, Tulandi T: Adhesion prevention in gynecologic surgery. Obstet Gynecol Surv 2004, 59(5):360-367.

2. Baakdah $H$, Tulandi T: Adhesion in gynecology complication, cost, and prevention: a review. Surg Technol Int 2005, 14:185-90.

3. Parker MC, Wilson MS, van Goor H, Moran BJ, Jeekel J, Duron JJ, Menzies D, Wexner SD, Ellis H: Adhesions and colorectal surgery - call for action. Colorectal Dis 2007, 9(Suppl 2):66-72.

4. Sileri P, Sthory R, McVeigh E, Child T, Cunningham C, Mortensen NJ, Lindsey I: Adhesions are common and costly after open pouch surgery. J Gastrointest Surg 2008, 12(7):1239-45.

5. van Goor H: Consequences and complications of peritoneal adhesions. Colorectal Dis 2007, 9(Suppl 2):25-34.

6. Ahmad G, Duffy JM, Farquhar C, Vail A, Vandekerckhove P, Watson A, Wiseman D: Barrier agents for adhesion prevention after gynaecological surgery. Cochrane Database Syst Rev 2008, , 2: CD000475.

7. Robertson D, Lefebvre G, Leyland N, Wolfman W, Allaire C, Awadalla A, Best C, Contestabile E, Dunn S, Heywood M, Leroux N, Potestio F, Rittenberg D, Senikas V, Soucy R, Singh S, SOGC: SOGC clinical practice guidelines: Adhesion prevention in gynaecological surgery: no. 243, June 2010. Int J Gynaecol Obstet 2010, 111(2):193-7.

8. Leroy J, Ananian P, Rubino F, Claudon B, Mutter D, Marescaux J: The Impact of Obesity on Technical Feasibility and Postoperative Outcomes of Laparoscopic Left Colectomy. Ann Surg 2005, 241(1):69-76.

9. Lin F, Zhang QJ, Zheng FY, Zhao HQ, Zeng QQ, Zheng MH, Zhu HY Laparoscopically assisted versus open surgery for endometrial cancer-a meta-analysis of randomized controlled trials. Int J Gynecol Cancer 2008, 18(6):1315-25.

10. Sica GS, laculli E, Benavoli D, Biancone L, Calabrese E, Onali S, Gaspari AL: Laparoscopic versus open ileo-colonic resection in Crohn's disease: short- and long-term results from a prospective longitudinal study. J Gastrointest Surg 2008, 12(6):1094-102.

11. Stumpf M, Klinge U, Tittel A, Brücker C, Schupelick V: The surgical trauma of abdominal wall incision: A comparison of laparoscopic vs open surgery with three-dimensional stereography. Surg Endosc 2001, 15(10):1147-1149.

12. Mynbaev OA, Corona R: Possible mechanisms of peritoneal tissue-oxygen tension changes during $\mathrm{CO} 2$-pneumoperitoneum: the role of design, methodology and animal models. Hum Reprod 2009, 24(6):1242-1246.

13. Hellebrekers BW, Emeis JJ, Kooistra T, Trimbos JB, Moore NR, Zwinderman KH, Trimbos-Kemper TC: A role for the fibrinolytic system in postsurgical adhesion formation. Fertil Steril 2005, 83(1):122-9.

14. Holmdahl L: The role of fibrinolysis in adhesion formation. Eur I Surg Suppl 1997, , 577: 24-31.

15. Kece C, Ulas M, Ozer I, Ozel U, Bilgehan A, Aydog G, Dalgic T, Oymaci E, Bostanci B: Carbondioxide pneumoperitoneum prevents postoperative adhesion formation in a rat cecal abrasion model. J Laparoendosc Adv Surg Tech A 2010, 20(1):25-30.

16. Ott DE: Laparoscopy and adhesion formation, adhesions and laparoscopy. Semin Reprod Med 2008, 26(4):322-30.

17. Molinas CR, Mynbaev O, Pauwels A, Novak P, Koninckx PR: Peritoneal mesothelial hypoxia during pneumoperitoneum is a cofactor in adhesion formation in a laparoscopic mouse model. Fertil Steril 2001, 76(3):560-567.

18. Nagelschmidt M, Gerbecks $D$, Minor $T$ : The impact of gas laparoscopy on abdominal plasminogen activator activity. Surg Endosc 2001, 15(6):585-8.

19. Winslow ER, Brunt LM: Perioperative outcomes of laparoscopic versus open splenectomy: A meta-analysis with an emphasis on complications. Surgery 2003, 134(4):647-653.

20. Chegini N: Peritoneal molecular environment, adhesion formation and clinical implication. Front Biosci 2002, 7:e91-115.

21. Dijkstra FR, Nieuwenhuijzen M, Reijnen MM, van Goor H: Recent clinical developments in pathophysiology, epidemiology, diagnosis and treatment of intra-abdominal adhesions. Scand I Gastroenterol Suppl 2000, 232: 52-59.
22. Liakakos T, Thomakos N, Fine PM, Dervenis C, Young RL: Peritoneal adhesions: etiology, pathophysiology, and clinical significance. Recent advances in prevention and management. Dig Surg 2001, 18(4):260-73.

23. Munireddy S, Kavalukas SL, Barbul A: Intra-abdominal healing: gastrointestinal tract and adhesions. Surg Clin North Am 2010, 90(6):1227-36.

24. Mynbaev OA, Adamyan LV, Mailova K, Vanacker B, Koninckx PR: Effects of adding small amounts of oxygen to a carbon dioxidepneumoperitoneum of increasing pressure in rabbit ventilation models. Fertil Steril 2009, 92(2):778-84, Epub 2008 Sep 27.

25. Mynbaev OA, Koninckx PR, Bracke M: A possible mechanism of peritoneal $\mathrm{pH}$ changes during carbon dioxide pneumoperitoneum. Surg Endosc 2007, 21(3):489-491.

26. Mynbaev OA, Molinas CR, Adamyan LV, Vanacker B, Koninckx PR: Pathogenesis of $\mathrm{CO}(2)$ pneumoperitoneum-induced metabolic hypoxemia in a rabbit model. J Am Assoc Gynecol Laparosc 2002, 9(3):306-314.

27. Mynbaev OA, Molinas CR, Adamyan LV, Vanacker B, Koninckx PR: Reduction of $\mathrm{CO}(2)$-pneumoperitoneum-induced metabolic hypoxaemia by the addition of small amounts of $\mathrm{O}(2)$ to the $\mathrm{CO}(2)$ in a rabbit ventilated model. A preliminary study. Hum Reprod 2002, 17(6):1623-1629.

28. Miyano G, Yamataka A, Doi T, Okawada M, Takano Y, Kobayashi H, Lane GJ, Miyano T: Carbon dioxide pneumoperitoneum prevents intraperitoneal adhesions after laparotomy in rats. J Pediatr Surg 2006, 41(5):1025-8.

29. Ziprin P, Ridgway PF, Peck DH, Darzi AW: Laparoscopic-type environment enhances mesothelial cell fibrinolytic activity in vitro via a downregulation of plasminogen activator inhibitor-1 activity. Surgery 2003, 134(5):758-65.

30. Berretta R, Rolla M, Patrelli TS, Gramellini D, Fadda GM, Nardelli GB: Incidence of port-site metastasis after laparoscopic management of borderline ovarian tumors: a series of 22 patients. Eur I Gynaecol Oncol 2009, 30(3):300-2.

31. Lundberg $\mathrm{O}$, Kristoffersson A: Pneumoperitoneum impairs blood flow and augments tumor growth in the abdominal wall. Surg Endosc 2004, 18(2):293-6.

32. Martínez A, Querleu D, Leblanc E, Narducci F, Ferron G: Low incidence of port-site metastases after laparoscopic staging of uterine cancer. Gynecol Oncol 2010, 118(2):145-50.

33. Mynbaev Ospan: Transplanted cancer cell metastatic syndrome in the peritoneum wounds or/and port-sites: Russian roulette in surgical oncology. MSc thesis VUB, Brussels-Ghent; 2006, 84[http://master-cgt.vub.ac. be/graduates.php].

34. Vergote I, Marquette $S$, Amant F, Berteloot P, Neven P: Port-site metastases after open laparoscopy: a study in 173 patients with advanced ovarian carcinoma. Int J Gynecol Cancer 2005, 15(5):776-9.

35. Corona R, Verguts J, Schonman R, Binda MM, Mailova K, Koninckx PR: Postoperative inflammation in the abdominal cavity increases adhesion formation in a laparoscopic mouse model. Fertil Steril 2011.

\section{Pre-publication history}

The pre-publication history for this paper can be accessed here: http://www.biomedcentral.com/1471-2482/11/30/prepub

doi:10.1186/1471-2482-11-30

Cite this article as: Pismensky et al:: Severe inflammatory reaction induced by peritoneal trauma is the key driving mechanism of postoperative adhesion formation. BMC Surgery 2011 11:30. 